ISSN 0819-2642

ISBN 0734025874

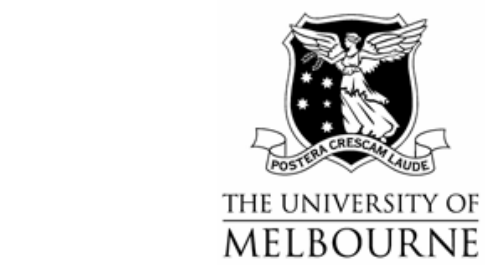

THE UNIVERSITY OF MELBOURNE

DEPARTMENT OF ECONOMICS

RESEARCH PAPER NUMBER 931

MARCH 2005

AN IN-WORK PAYMENT WITH AN

HOURS THRESHOLD: LABOUR SUPPLY

AND SOCIAL WELFARE

by

John Creedy

Department of Economics

The University of Melbourne

Melbourne Victoria 3010

Australia. 


\title{
An In-Work Payment With an Hours Threshold: Labour Supply and Social Welfare
}

\author{
John Creedy* \\ The University of Melbourne
}

\begin{abstract}
This paper uses an optimal tax framework to examine the effect on a measure of social welfare of an in-work payment, involving a discontinuity at an hours threshold. Social welfare is defined in terms of individuals' utilities, which depend on leisure and net income. The in-work payment augments a modified minimum income guarantee having two tax rates. Numerical simulations, which ensure that a fixed amount of net revenue per person is collected by the government, show that social welfare falls systematically as the extent of the discontinuity increases, and as the hours threshold, at which the jump in net income occurs, increases. Eliminating the discontinuity resulting from the in-work payment therefore improves social welfare.

JEL codes: H21; H31; H53
\end{abstract}

Keywords: social welfare; in-work payment; hours threshold; labour supply

${ }^{*}$ I should like to thank Nathan McClellan, Dean Hyslop and Dave Mare for comments on an earlier version. 


\section{Introduction}

The aim of this paper is to examine the implications for labour supply and social welfare, defined in terms of individual's utilities, of the presence of an in-work transfer payment involving a discontinuity. This discontinuity arises from the use of an hours threshold, such that net income increases at a specified hours threshold. ${ }^{1}$ Budget constraints facing individuals often have small discontinuities arising from the difficulties of integrating a number of different types of transfer payment. These are typically regarded as shortcomings. However, a major motivation for a jump in net income of this kind is that it is thought to provide an incentive for relatively low-wage individuals to increase their labour supply up to the threshold level. One suggested rationale for this is that individuals are expected to have longer term benefits from such attachment to the labour market, such as increased productivity and other characterisitics. $^{2}$

The following analysis uses a highly simplified tax structure and allows only for variations in wage rates among individuals. That is, the standard optimal income tax framework is applied, and individuals are assumed to maximise utility defined in terms of net income and leisure time. In making comparisons among alternative tax structures, attention is given to the government's budget constraint and all results are for budget neutral structures. A fixed amount of non-transfer government revenue is required. ${ }^{3}$ The emphasis is on using numerical simulations in order to clarify the properties of alternative tax and benefit systems. Analytical solutions are not available even in the simplest of models. It is necessary to stress that the analysis in this paper is exclusively of the supply side of the labour market, with wage

\footnotetext{
${ }^{1} \mathrm{~A}$ description of the working tax credit, which involves a bonus payment at 16 hours and 30 hours (for families with and without children respectively) in the UK is in Brewer (2003). For empirical studies of labour supply effects, see Duncan and Giles $(1996,1998)$. Other forms of in-work payment, such as the US earned income tax credit, are phased in rather than introducing a discontinuity.

${ }^{2}$ Sometimes a concern is expressed, in a standard means tested system, over benefits being paid to high wage but very low hours individuals. However, it is not clear how large this group is in practice.

${ }^{3}$ For further discussion of the optimal tax framework, see Atkinson and Stiglitz (1980), Tuomala (1990) and Creedy (1996).
} 
rates assumed to remain fixed. The ultimate effects of any tax and transfer reform obviously depend also on labour demand considerations. There is a range of administration and other issues associated with this type of tax reform. These include the difficulty of monitoring hours worked and the problem of dealing with variability in hours over time. The latter can lead to horizontal equity problems. However, these issues are not examined here.

The basic specification of the tax structure is described in section 2 . This is a flexible structure containing few parameters, but is nevertheless capable of displaying all the main features of complex budget constraints. In particular, these concern the characteristics of labour supply behaviour generated by kinks and non-convexities in the budget set. The modelling procedure is outlined in section 3. This describes the utility functions, the social evaluation function and the strategy used for obtaining budget neutral comparisons. Numerical simulations are reported in section 4. Results are reported for social welfare and inequality, for variations in the hours threshold and in the extent of the jump in net income produced by the in-work payment. Brief conclusions are in section 5 .

\section{The Tax and Transfer System}

This section describes the tax and transfer system examined. The budget constraints need to be specified in detail, in view of the later need to compute optimal hours of work for each individual. An in-work payment (IWP), which becomes available at a particular hours threshold, is used to augment a two-rate means-tested tax structure, often described as a modified minimum income guarantee. The various forms taken by budget constraints, depending on the wage rate faced by the individual, along with the resulting labour supply functions, are discussed.

\subsection{Budget Constraints}

A convenient way to model an in-work payment with an hours threshold is to consider it as being added onto a basic tax and transfer system involving only two effective marginal rates. Suppose that all those with earnings, $y$, 
below an earnings threshold, $a$, receive a benefit equal to $s(a-y)$, where $s$ is the taper or abatement rate at which the benefit is withdrawn as earnings increase. After this benefit is exhausted, earnings are taxed at a constant proportional rate, so that the tax paid is $t(y-a)$; this is effectively a proportional tax applied to earnings in excess of a tax free threshold of $a$. For an individual with an hourly wage rate of $w$, and working $h$ hours a week, the earnings threshold is reached where $a=w h$, that is at the hours level $a / w$. This system is shown in Figure 1 as the line AKE. For this means-tested system, the abatement rate exceeds the tax rate, so that $s>t$. Each budget constraint in Figure 1 is drawn for a particular wage rate, and the lower part of the figure has a higher wage than the upper diagram. Hence the individual with the higher wage reaches the tax-free threshold, $a$, at a lower hours level.

The modified minimum income guarantee used here has several analytical advantages. It involves just two tax rates and one earnings threshold. The minimum income available to those who do not work is defined in terms of the benefit taper rate and the earnings threshold, since when $y=0$, the benefit is at. The use of a single threshold is convenient for the analysis of budget neutral alternatives, as this one parameter can be allowed to adjust while others are varied. The specification also explicitly avoids any further discontinuities in budget constraints. It can be seen below that even an apparently simple system of this kind involves considerable complexities. ${ }^{4}$

Suppose that this basic system is augmented by an in-work payment whereby net income increases by an amount $g_{w}$ at the hours level, $h_{1}$. Beyond this discontinuity in the budget constraint, the effective abatement rate is $r$, where $s>r>t$. This means that the new section of the budget constraint, CD in Figure 1, must reach the old constraint somewhere along the range KE. This occurs at the hours level $h_{2}$, where $h_{2}>a / w$. Here $h_{2}$ depends on the individual's wage rate, while $h_{1}$ is fixed and is the same for all individuals. Benefit receipt is thus extended further up the hours, and thus earnings, range compared with the basic transfer system.

The extent of the discontinuous jump in the budget constraint, $g_{w}$, must

\footnotetext{
${ }^{4}$ This type of means-tested system has been examined in detail in Lambert $(1985,1988)$ and Creedy $(1996,1997)$.
} 


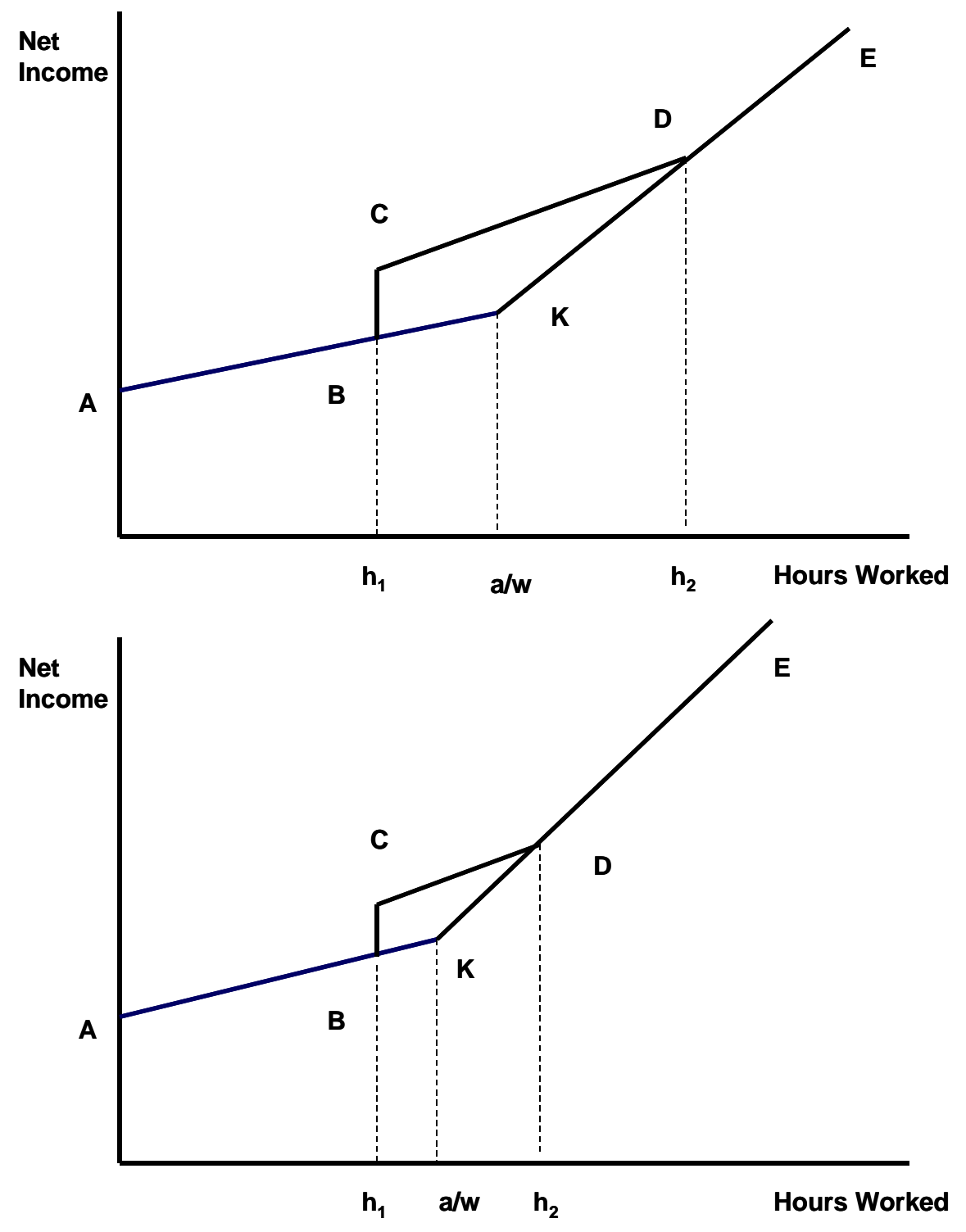

Figure 1: Budget Constraints For Two Wage Rates 
be lower for those with higher wage rates, otherwise the in-work payment would continue to be paid to very high-income individuals (those with high $w$ and working at least $h_{1}$ hours). The question arises of how to specify this reduction. Suppose that the highest value, of $g_{w}=g$, occurs for the minimum wage, $w_{m}$. For higher wage rates, the vertical jump in the budget line at $h_{1}$ is assumed to decline at a linear rate. A convenient specification for this is:

$$
\begin{aligned}
g_{w} & =g-v\left(w h_{1}-w_{m} h_{1}\right) \\
& =g-v h_{1}\left(w-w_{m}\right)
\end{aligned}
$$

The decline in $g_{w}$ therefore depends on the extent to which gross earnings at the specified hours threshold exceed the earnings of someone with the minimum wage. Hence there is no in-work payment for $w$ in the range:

$$
w>w_{m}+\frac{g}{v h_{1}}
$$

However, the value of $v$ cannot be set arbitrarily. Net income at $h_{1}$ for wage $w>w_{m}$ must exceed that for $w_{m}$ at the same hours level. Otherwise the system is 'incentive incompatible' and those with higher wages have an incentive to pretend to have lower wage rates. This means that:

$$
a s+w h_{1}(1-s)+g-v h_{1}\left(w-w_{m}\right)>a s+w_{m} h_{1}(1-s)+g
$$

or:

$$
h_{1}\left(w-w_{m}\right)(1-s-v)>0
$$

which implies that $s+v<1$.

Denoting net income as $z$, the equation of segment $\mathrm{AB}$ in Figure 1, over the hours range $0<h<h_{1}$, is therefore given by:

$$
\begin{aligned}
z & =w h+s(a-y) \\
& =a s+w h(1-s)
\end{aligned}
$$

The equation of the segment DE, where $h>h_{2}$, is:

$$
z=a t+w h(1-t)
$$




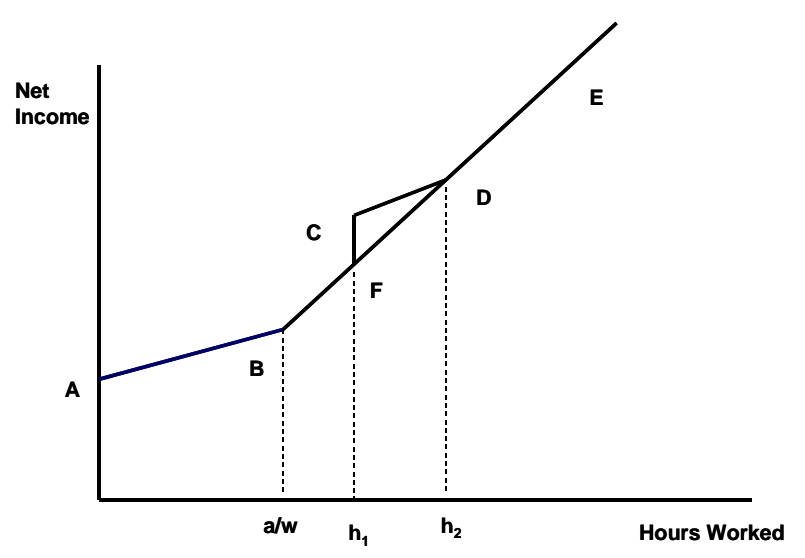

Figure 2: A Budget Constraint With $a / w<h_{1}$

The equation of CD, for which $h_{1}<h<h_{2}$, is:

$$
\begin{aligned}
z & =a s+w h_{1}(1-s)+g_{w}+w(1-r)\left(h-h_{1}\right) \\
& =a s+g-w h_{1}(s-r)-v h_{1}\left(w-w_{m}\right)+w h(1-r)
\end{aligned}
$$

Hence the intersection of CD and DE, at D, occurs for hours equal to $h_{2}$, where:

$$
h_{2}=\frac{a(s-t)+g-h_{1}\left\{w(s-r)+v\left(w-w_{m}\right)\right\}}{w(r-t)}
$$

As the wage rate increases, the hours level corresponding to the kink at $\mathrm{K}$ moves to the left, and the height BC falls. This is demonstrated in Figure 1, where the lower section shows the budget constraint for a higher wage than in the upper section.

Eventually the wage is such that $a / w<h_{1}$ while the in-work payment is still received. Hence in this case, $a / h_{1}<w<w_{m}+g / r h_{1}$. This situation is shown in Figure 2. In this case the equation of the linear segment CD is:

$$
\begin{aligned}
z & =\left\{a t+w h_{1}(1-t)+g-v h_{1}\left(w-w_{m}\right)\right\}+w(1-r)\left(h-h_{1}\right) \\
& =a t+w h_{1}(r-t)+g-v h_{1}\left(w-w_{m}\right)+w h(1-r)
\end{aligned}
$$

Thus, when $h_{1}>a / w$, the in-work payment is exhausted at $h_{2}$ hours, where:

$$
h_{2}=h_{1}+\frac{g-v h_{1}\left(w-w_{m}\right)}{w(r-t)}
$$




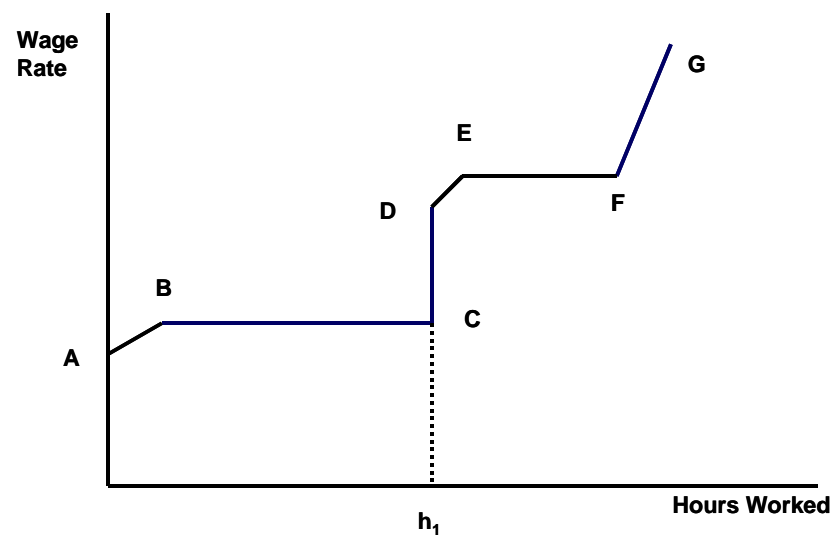

Figure 3: A Possible Labour Supply Function

The non-convexities arising from the fact that $s>r>t$, combined with the non-convexity in the budget constraint arising from a discontinuity at a fixed hours threshold, gives rise to unusual labour supply behaviour. This is discussed in the following subsection.

\subsection{Labour Supply}

The labour supply function can take several forms with this type of tax and transfer scheme. The complexities arise because of the non-convexities in the budget set. Figure 3 shows a possible form where, after a minimum wage level, a higher wage leads to increased labour supply along the segment AB of the budget constraint. Then there is a jump to the corner at $h_{1}$. Labour supply remains fixed at this hours threshold for a range of wage rates, before movement takes place along the range where the in-work payment is subject to abatement at the rate $r$. Finally, another jump is made to the segment where the marginal rate is $t$. However, if the taper or abatement rates $r$ and $s$ are relatively high, it is likely that there is simply one jump from zero hours of work to $h_{1}$, followed by another jump directly from $h_{1}$ to the segment where no benefits are received and the marginal tax rate is $t$. This is shown in Figure 4.

This framework can in some cases give rise to a reduction in labour supply as the wage rate increases, particularly if the hours threshold $h_{1}$ is relatively 


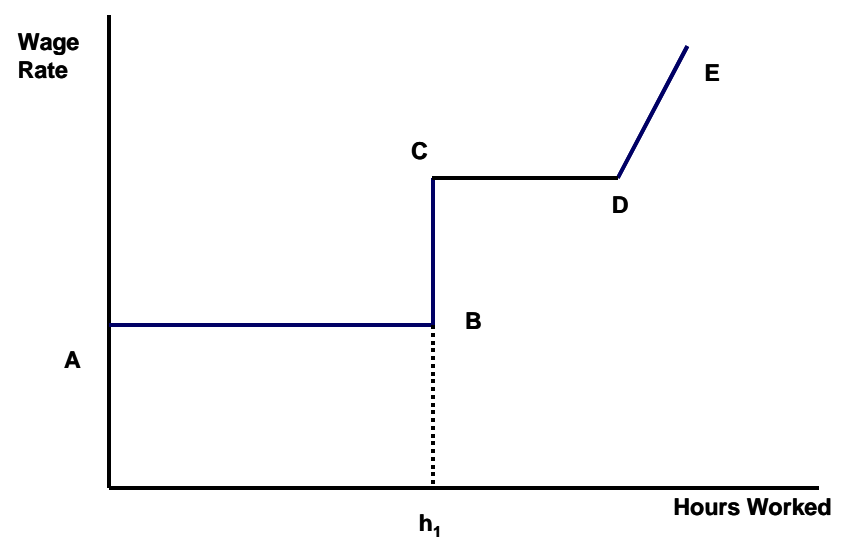

Figure 4: Labour Supply With High Abatement Rates

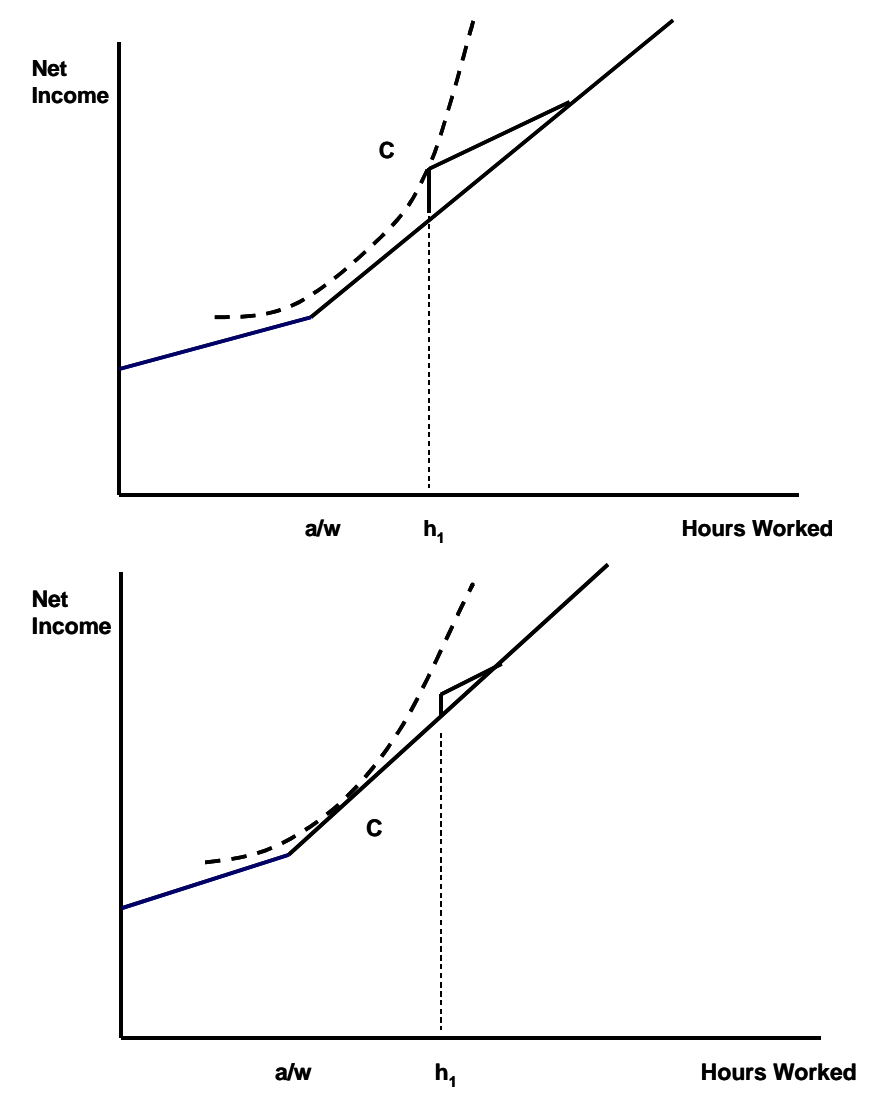

Figure 5: Labour Supply With High Hours Threshold 
large. Figure 5 shows the situation where labour supply is $h_{1}$ for a range of wage rates, but a point is reached where an increase in $w$ leads to a reduction in labour supply. This arises because the discontinuity falls as $w$ increases, even though, as discussed above, net income is higher at comparable hours. However, this case is unlikely to apply to most values of $h_{1}$ that are considered in practice.

\section{The Modelling Procedure}

This section describes the simulation procedure used to obtain numerical results. Further analysis requires an explicit assumption about preferences, and the assumption is made that individuals have Cobb-Douglas utility functions defined in terms of net income and leisure. More complex utility functions, such as the CES form, could be used, but are unlikely to affect the main comparisons below. The main characteristics of labour supply are driven, as seen above, by the nonlinear nature of the budget constraints rather than the properties of utility functions. ${ }^{5}$ The functions and a procedure for obtaining optimal hours worked for each individual are described in the next subsection. The model is completed by the specification of a wage rate distribution. This, along with the social evaluation function used, is discussed in the second subsection.

\subsection{Utility Functions}

Suppose for convenience that utility functions follow the Cobb-Douglas form:

$$
U=c^{\alpha}(T-h)^{1-\alpha}
$$

where $T$ is the maximum amount of time available per week, and $c$ is an index of total consumption, whose price is normalised to unity. Hence, in this static framework, $c$ is equivalent to net income, $y$. Consider tangency solutions along a linear budget constraint segment given by:

$$
c=b+w_{n} h
$$

\footnotetext{
${ }^{5}$ On the use of the CES form, see Creedy $(1996,1997)$.
} 
where $w_{n}$ is the net wage rate and $b$ is the virtual income appropriate to the particular segment. ${ }^{6}$ In this case, full income, $M$, is equal to $T w_{n}+b$ and following the standard Cobb-Douglas results, $c=\alpha M$ and leisure, $T-h$, is equal to $(1-\alpha) M / w_{n}$. Hence hours worked are given by: ${ }^{7}$

$$
h=\alpha T-\frac{b(1-\alpha)}{w_{n}}
$$

The tax and transfer scheme described above combines a piecewise-linear budget constraint with non-convexities and a discontinuity. It can therefore give rise to multiple local optima. A procedure for solving the labour supply, given a wage rate, taste parameter and the parameters of the tax system, must involve examination of utility at the possible corner solutions and the use of (13) to search for tangency positions (by appropriate substitution of the net wage and virtual income), checking that such solutions fall within the relevant hours limits.

The algorithm must begin by determining whether $w$ is such that the in-work payment is relevant and, if so, whether the budget constraint is like Figure 1 or Figure 2. In the latter case, the search for local optima includes four segments where tangency positions may be relevant. It is necessary to collect all interior and corner solutions and then find the one that gives rise to the maximum utility.

\subsection{Evaluation Procedure}

This subsection describes the procedure used to evaluate alternative tax systems, that is alternative parameter values for the flexible system described in section 2. Consider a population of individuals facing the same tax system. It is assumed that tastes are identical, but each individual faces a different wage rate. Suppose the wage rate distribution, for wages above $w_{m}$, follows the lognormal form, so that $w$ is distributed as $\Lambda\left(w \mid \mu, \sigma^{2}\right)$ where $\mu$ and

\footnotetext{
${ }^{6}$ Virtual income is the intercept (net income) of the segment, when it is extended to the axis where hours of work are zero.

${ }^{7}$ Full income is the total net income if all available time is spent working, that is if $h=T$. The individual is considered to convert the endowment of time (combined with non-wage income) into full income, and use this to purchase goods and leisure, at a price equal to the net wage.
} 
$\sigma^{2}$ are respectively the mean and variance of log-wage rates. An artificial population can be generated by drawing observations at random from this lognormal distribution and setting any $w<w_{m}$ equal to $w_{m}$.

In the model considered here, there are seven tax parameters, $s, t, r$, $a, g, h_{1}$ and $v$. However, these cannot all be set independently because of the need to satisfy the government's budget constraint. The tax parameters must be such that, allowing for the endogenous labour supplies generated by the taxes and the wage rate distribution (along with the taste parameter), sufficient revenue is raised to cover the expenditure on transfer payments as well as an amount of non-transfer expenditure per person.

The government's budget constraint is highly complex in view of the nature of the constraints facing individuals; hence it is not possible to write one of the tax parameters as a function of the other parameters. A numerical method of solution is required, and it is appropriate to solve for the earnings threshold, $a$, for given values of the other parameters. Any value of $a$ is consistent with, for example, both low and high values of tax rates (in view of labour supply behaviour), so it is not sensible to try to solve for, say, $t$, given values of $a$ and the other parameters.

The approach followed here is to evaluate the tax and transfer system using a social welfare function expressed in terms of individuals' utilities. The welfare function is the iso-elastic form commonly used in the optimal tax literature, and is written as:

$$
W=\sum_{i=1}^{n} \frac{U_{i}^{1-\varepsilon}}{1-\varepsilon}
$$

where $\varepsilon$ represents the constant relative inequality aversion. It is convenient to rewrite (14) in abbreviated form as: ${ }^{8}$

$$
W=\bar{U}\left(1-I_{U}\right)
$$

where $\bar{U}$ and $I_{U}$ are respectively the arithmetic mean utility and its inequality, as measured by the Atkinson index, $I_{U}=1-U_{E} / \bar{U}$ and $U_{E}$ is the equally distributed equivalent utility. ${ }^{9}$

\footnotetext{
${ }^{8}$ On abbreviated social welfare functions, see Lambert (1993). On the associated inequality measure, see Atkinson (1970).

${ }^{9}$ In optimal tax calculations it is known that results depend on the particular cardi-
} 


\section{Simulation Analysis}

This section provides simulation results using the framework described above. In view of the large number of parameters, no attempt is made here to search over all dimensions to produce optimal tax rates. Instead, the emphasis is on the effects of the size of the discontinuity in budget constraints and the value of the hours threshold at which the jump in net incomes occur. Hence this section concentrates on the results of varying the parameters $g$ and $h_{1}$. The first subsection describes the other parameter values used, while the second subsection gives the main results of the comparisons.

\subsection{Parameter Values}

In view of the stylised nature of the model, it is necessary to consider parameter values which produce sensible numerical results; that is, the orders of magnitude of various population characteristics must bear some relation to observed magnitudes. Results are given here for just one basic set of parameters (except for $g$ and $h_{1}$ which are varied) it is important to stress the need, in this type of exercise, to carry out extensive sensitivity analyses. It was found that the main features of the reported results are robust to variations in parameter values.

The values assumed for $s, r, t$ and $v$ are respectively 0.8, 0.6, 0.4 and 0.1 . The taste parameter $\alpha$ is equal to 0.55 and the maximum time per week available for work, $T$, is set to 80 . The arithmetic mean hourly wage $\bar{w}$ is 19 , while the variance of logarithms of the wage rate distribution, $\sigma^{2}$, is 0.5 ; the implied value of the arithmetic mean log-wage is given, from the properties of the lognormal distribution, by $\mu=\log \bar{w}-\sigma^{2} / 2$. If the values of $g$ and $h_{1}$ are set at 60 per week and 30 hours respectively, and if non-transfer government revenue per person is 25 per week, it is found that a value of $a=250$ is required for a balanced budget.

The social welfare function requires a value of relative inequality aversion,

nalisation of utility functions used, though of course the cardinalisation does not affect individuals' optimal labour supplies. However, this is not an issue in the present context. 
$\varepsilon$, to be specified. The following results are for $\varepsilon=0.5{ }^{10}$ All simulations are for a population of 5000 individuals.

\subsection{Some Results}

In view of the emphasis on the two parameters $g$ and $h_{1}$ of the in-work payment, this section examines the implications of varying each one of these in turn, for specified values of the other parameter. In all cases, $a$ is endogenously adjusted to ensure budget neutrality. Figure 6 shows the variation in $W$ as the jump in net income, $g$, varies, for three values of the hours threshold, $h_{1}$. It can clearly be seen that social welfare falls systematically as $g$ increases, although there is a very slight rise for increases at very high values of $g$. For the lower value of $h_{1}=25$, the profile is flat for low values of $g$. This is because the discontinuity actually has no effect over this range: individuals either do not work or they work and pay tax at the rate $t$. Beyond $g$ of about 60 , the profile for $h_{1}=25$ is again flat. Here there are no non-workers, lowwage individuals (for $w$ below about 14) are at 25 hours, and those between about 14 and 18 per hour receive an abated in-work payment over this range of the schedule.

Figure 7 shows the variation in social welfare as the hours threshold, $h_{1}$, varies for three values of the discontinuous jump, $g$. Again it can be seen that social welfare unambiguously falls as the threshold is increased. ${ }^{11}$

Faced with these results it is of interest to compare the basic modified minimum income guarantee scheme with the structure having an additional in-work payment. For $g=60$ and $h_{1}=30$, it is found (for values of other parameters as discussed above) that $W=170$. Eliminating the in-work payment altogether is achieved by setting $g=0$ and correspondingly increasing

\footnotetext{
${ }^{10}$ In the context of incomes, $x$, for individuals $i$ and $j$, with $x_{j}>x_{i}$, then $\left.\frac{d x_{i}}{d x_{j}}\right|_{W}=$ $-\left(\frac{x_{j}}{x_{i}}\right)^{\varepsilon}$. Hence, if $j$ has twice the income of $i$, a value of $\varepsilon=1$ means that the judge is prepared to take $\$ 1$ from $j$ and transfer only 50 cents to $i$, losing the remaining 50 cents. For survey results on attitudes to inequality, producing values of $\varepsilon$ substantially below 1 , see Amiel et al. (1999).

${ }^{11}$ If $h_{1}$ is set very low, then obviously even those on minimum wages would work at $h_{1}$ and if it is set high, the labour supply response discussed above arises (where hours fall as the wage increases).
} 


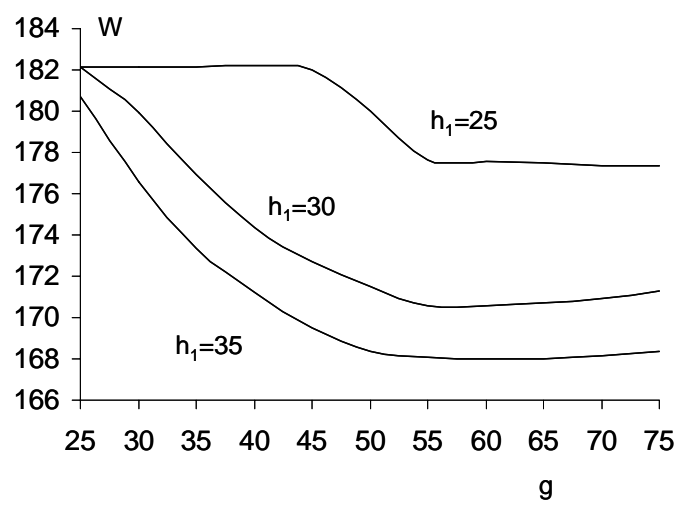

Figure 6: Social Welfare And The Discontinuity

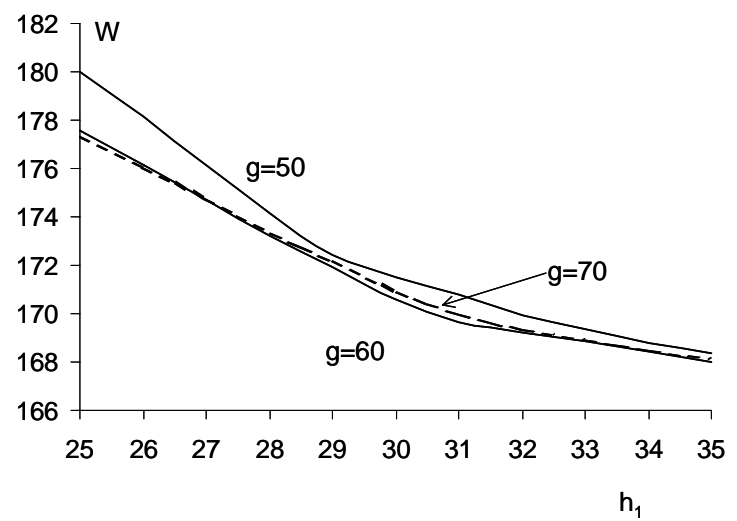

Figure 7: Social Welfare And The Hours Threshold 


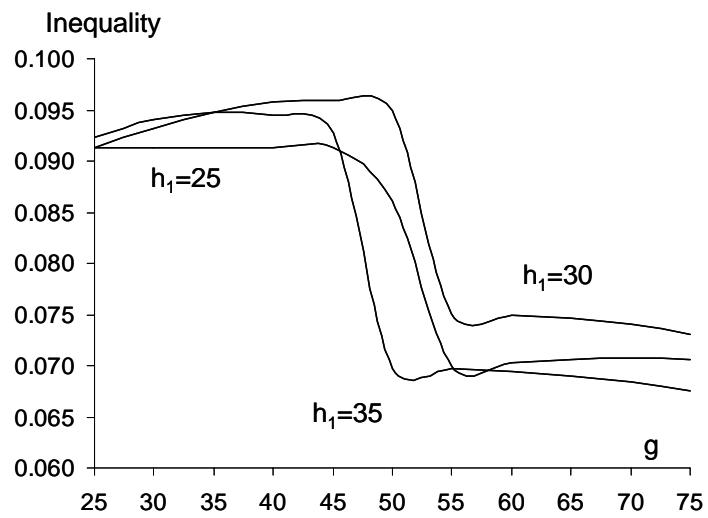

Figure 8: Inequality And The Discontinuity

the earnings threshold, $a$, to maintain budget neutrality. This produces a value of social welfare of $W=182$. How does the in-work payment compare with a policy that encourages work by instead lowering the effective marginal tax rate facing those in receipt of benefits? It is found, for example, that if $s$ is reduced from 0.8 to 0.7 (with $g=0$ ), social welfare increases yet again to 184. Hence reducing the discontinuity is welfare improving, and flattening the tax rate structure is further welfare enhancing.

The optimal tax approach used here evaluates tax structures in terms of social welfare, defined over individuals' utilities. This allows for the consumption of leisure time in addition to net income. However, it is also of interest to examine the effect of the in-work payment on the inequality of net income. Results, for the Atkinson inequality measure (again for $\varepsilon=0.5$ ), are shown in Figure 8, for variations in $g$, and Figure 9, for variations in $h_{1}$. Figure 8 shows a reduction in inequality over a narrow range of $h_{1}$ : here the inequality of net income falls when a significant number of individuals move to the hours threshold.

Finally, Figure 10 gives an idea of the typical labour supply functions obtaine, where hours of work are measured on the vertical axis. As suggested in section 2 , the corner solutions at $h=0$ and at $h=h_{1}$ dominate for lower wage levels. The different combinations of $h_{1}$ and $g$ determine only the height and position of the steps in the diagram. 


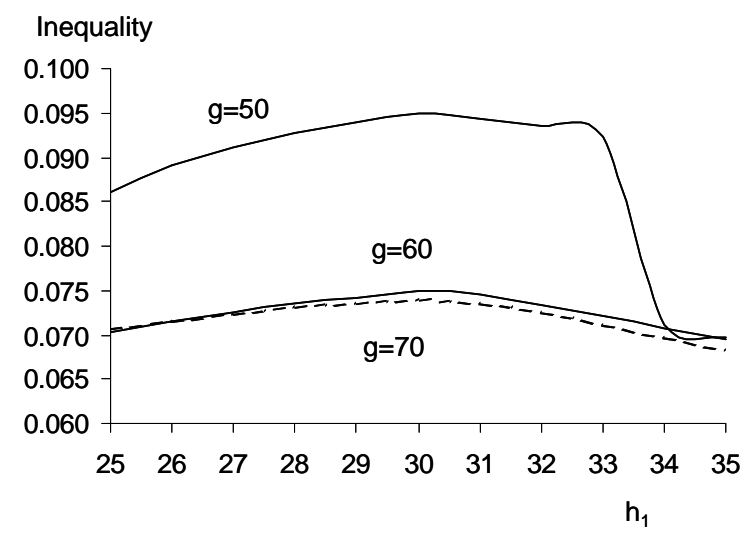

Figure 9: Inequality of Net Income And The Hours Threshold

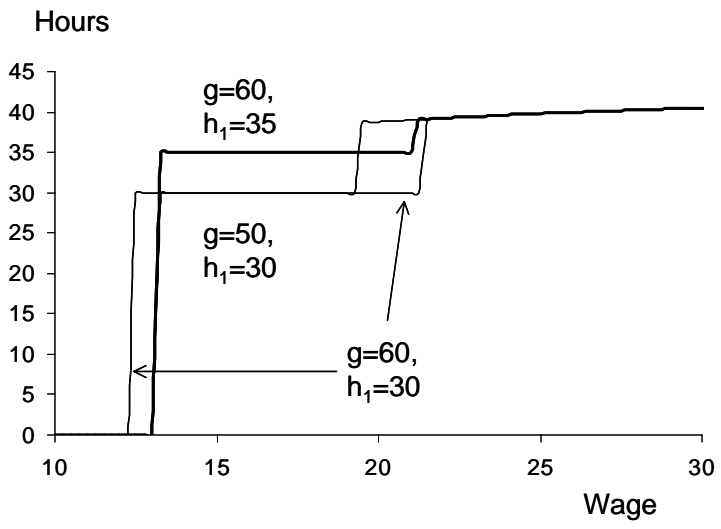

Figure 10: Labour Supply Curves 


\section{Conclusions}

This paper has used an optimal tax framework to examine the effect on a measure of social welfare of an in-work payment, involving a discontinuity at an hours threshold. The in-work payment augments a modified minimum income guarantee having two tax rates. Social welfare is defined in terms of individuals' utilities, which depend on terms of leisure and net income. Numerical simulations, which ensure that a fixed amount of net revenue per person is collected by the government, show that social welfare falls systematically as the extent of the discontinuity increases, and as the hours threshold, at which the jump in net income occurs, increases. Eliminating the discontinuity resulting from the in-work payment therefore improves social welfare. Furthermore, it was found that a policy of improving labour supply incentives, by flattening the rate structure in the modified minimum income guarantee, increased social welfare yet further. 


\section{References}

[1] Amiel, Y., Creedy, J. and Hurn, S. (1999) Measuring attitudes towards inequality. Scandinavian Journal of Economics, 101, pp. 83-96.

[2] Atkinson, A. B. (1970) On the measurement of inequality. Journal of Economic Theory, 2, pp. 244-263.

[3] Atkinson, A. B. and Stiglitz, J. E. (1980) Lectures on Public Economics, New York: McGraw Hill.

[4] Brewer, M. (2003) The new tax credits. IFS Briefing Note, no. 35.

[5] Creedy, J. (1996) Fiscal Policy and Social Welfare : An Analysis of Alternative Tax and Transfer Systems, Edward Elgar, Aldershot.

[6] Creedy, J. (1997), 'Means-tested versus universal transfers: alternative models and value judgements', Manchester School, 66, 100-117.

[7] Duncan, A.S. and Giles, C. (1996) Labour supply incentives and recent family credit reforms. Economic Journal, 106, pp. 142-155.

[8] Duncan, A.S. and Giles, C. (1998) The labour market inpact of the working families tax credit in the UK. (Paper presented to International Institute for Public Finance conference, Cordoba, Argentina).

[9] Lambert, P.J. (1985), 'Endogenising the income distribution: the redistributive effect, and Laffer effects, of a progressive tax-benefit system', European Journal of Political Economy, 1, 3-20.

[10] Lambert, P. J. (1988), 'The equity-efficiency trade-off: Breit reconsidered', Oxford Economic Papers, 42, 91-104.

[11] Lambert, P. J. (1993) The Distribution and Redistribution of Income: A Mathematical Treatment. Manchester; Manchester University Press.

[12] Tuomala, M. (1990) Optimal Income Taxation and Redistribution. Clarendon Press, Oxford. 


\section{University Library}

\section{- M M I N E R VA A gateway to Melbourne's research publications}

Minerva Access is the Institutional Repository of The University of Melbourne

Author/s:

Creedy, J.

Title:

An in-work payment with an hours threshold: labour supply and social welfare

Date:

2005-03

Citation:

Creedy, J. (2005) An in-work payment with an hours threshold: labour supply and social welfare.

Persistent Link:

http://hdl.handle.net/11343/34199 